\title{
THE CLAMSHELL INCISION FOR BILATERAL PULMONARY ARTERY RECONSTRUCTION IN TETRALOGY OF FALLOT WITH PULMONARY ATRESIA
}

Giovanni Battista Luciani, $\mathrm{MD}^{\mathrm{a}}$

Winfield J. Wells, MD ${ }^{\mathrm{a}}$

Apichai Khong, $\mathrm{MD}^{\mathrm{b}}$

Vaughn A. Starnes, $\mathrm{MD}^{\mathrm{a}}$
Background: Patients with tetralogy of Fallot/pulmonary atresia often have bilateral pulmonary artery lesions, including diminutive central and peripheral vessels, major aortopulmonary collaterals, and distortion from previous operations. Staged procedures through lateral thoracotomies and median sternotomies have traditionally been used for repair. Methods: Between October 1993 and December 1995, 10 patients 3 months to 15 years old with complex tetralogy of Fallot/pulmonary atresia underwent repair via a clamshell approach. Nine had undergone a mean of $2.8 \pm 0.8$ previous operations (range 1 to 4 ). Indications for operation were repair of pulmonary artery arborization anomalies in 10 (4 unilateral, 6 bilateral), with unifocalization in 6 ( 2 unilateral, 4 bilateral). Results: Eight of 10 patients had concomitant complete repair. There were no deaths at a mean follow-up of $17.1 \pm 4.0$ months (range 12 to 26 ). Mean ventilation time was $3.7 \pm 2.1$ days (range 1 to 14 ) and hospital stay $8.7 \pm 4.6$ days (range 4 to 19). At follow-up, the peak right ventricular/left ventricular pressure ratio in patients who received complete repair was $0.44 \pm 0.13(0.30$ to 0.67$)$. One patient $(10 \%)$ required reoperation because of pseudoaneurysm of the main pulmonary artery 14 months after repair, and one had successful stent placement because of recurrent left and right pulmonary artery stenosis 8 months after repair. Two infants who underwent complete unifocalization and central pulmonary artery reconstruction are awaiting completion of repair. Conclusions: The clamshell approach to complex tetralogy of Fallot/ pulmonary atresia provides simultaneous exposure of bilateral central and peripheral pulmonary artery lesions and intracardiac pathologic conditions. This procedure appears safe and may decrease the number of operations required to complete repair of tetralogy of Fallot/pulmonary atresia in selected patients. (J Thorac Cardiovasc Surg 1997;113:443-52)
$T_{\text {og }}^{\text {he }}$ he goal of surgical treatment of complex tetralogy of Fallot/pulmonary atresia (ToF/PA) is the unifocalization of the arterial blood supply, the

From the Divisions of Cardiothoracic Surgery a and Cardiology, Children's Hospital Los Angeles, and the Departments of Surgery $^{\mathrm{a}}$ and Pediatrics, ${ }^{\mathrm{b}}$ USC School of Medicine, Los Angeles, Calif.

Presented in part at the Sixty-eighth Scientific Sessions of the American Heart Association, Nov. 13-16, 1995, Anaheim, Calif.

Received for publication April 15, 1996; revisions requested May 24, 1996; revisions received Sept. 5, 1996; accepted for publication Sept. 9, 1996.

Address for reprints: Giovanni Battista Luciani, MD, Division of Cardiac Surgery, University of Verona, O.C.M. Piazzale Stefani 1, Verona, 37126, Italy.

Copyright $(0) 1997$ by Mosby-Year Book, Inc.

$0022-5223 / 97 \$ 5.00+0 \quad \mathbf{1 2 / 1 / 7 7 8 6 1}$ reconstruction of the central pulmonary arteries, the establishment of right ventricle (RV)-to-pulmonary artery continuity, and, last, the correction of intracardiac defects. ${ }^{1}$ The major factor limiting complete anatomic repair is the degree of natural underdevelopment or iatrogenic distortion of the pulmonary vasculature, which can affect the recreation of an unobstructed, compliant pulmonary arterial vascular system. ${ }^{2-5}$

The traditional surgical approaches to complex ToF/PA have been staged operations aimed at stepwise correction of extracardiac and intracardiac anomalies. Several institutions have proposed techniques that entail preliminary unifocalization of the pulmonary arterial blood supply, via thoracotomies, and subsequent connection of the RV to the reconstructed pulmonary arteries with or without closure of the ventricular septal defect (VSD), via sternot- 
Table I. Patient demographics ( $n=10$ patients)

\begin{tabular}{lccc}
\hline \multicolumn{1}{c}{ Parameter } & Range & Mean $\pm S D$ & Median \\
\hline Sex (M/F) & $4 / 6$ & & \\
Age (yr) & $0.25-15$ & $6.7 \pm 5.1$ & 6.2 \\
Weight $(\mathrm{kg})$ & $3-35$ & $20.1 \pm 12.7$ & 19.2 \\
NYHA class & $3-4$ & $3.4 \pm 0.5$ & 3.4 \\
Previous operations & $1-4$ & $2.8 \pm 0.8$ & 3 \\
$\quad$ (No./patient) & & & \\
\hline
\end{tabular}

$S D$, Standard deviation; $M$, male; $F$, female; $N Y H A$, New York Heart Association.

omies. ${ }^{6-9}$ Recent clinical work has instead focused on the early establishment of RV-to-pulmonary artery continuity, as opposed to complete unifocalization, to promote growth of the pulmonary vascular bed. ${ }^{10}$ Common to all these treatment strategies has been the need for multiple ( 2 to 5 ) interventions and the low ( $20 \%$ to $50 \%$ ) proportion of patients in whom complete repair has been achieved. An alternative surgical approach has been proposed that consists of primary complete unifocalization and repair of ToF/PA and major aortopulmonary (AP) collateral arteries via a median sternotomy. ${ }^{11}$ Although the resulting reduction in the number of operations and the functional results have been encouraging, this method may prove challenging in patients who have had previous operations. ${ }^{11}$

At the Children's Hospital of Los Angeles, we have treated a population of patients with previously palliated ToF/PA, who were initially seen with residual or recurrent bilateral disease of the pulmonary arteries, AP collaterals, and intracardiac defects (complex ToF/PA). Reported herein is the retrospective review of our experience with the bilateral thoracosternotomy (clamshell) approach for completion of repair or of unifocalization in infants and children with complex ToF/PA.

\section{Methods}

Patients. Between October 1993 and December 1995, all children with ToF/PA and critical pulmonary artery lesions, including diminutive to absent and/or distorted central and peripheral branches, with or without major AP collateral arteries (complex ToF/PA) were treated by the present surgical approach.

Two infants and eight children were seen with complex ToF/PA during the observation interval. There were four boys and six girls, with ages ranging from 4 months to 15 years (median 6.2 years) and body weights ranging from 3 to $35 \mathrm{~kg}$ (median $19.2 \mathrm{~kg}$ ) (Table I). Diagnosis was confirmed by angiography in all patients. One patient was seen as a newborn infant with profound cyanosis, whereas the remaining nine had previously undergone examination and operation at different institutions. All patients had marked symptoms with cyanosis and congestive heart failure (median preoperative New York Heart Association class 3.4) (Table I).

Preoperative anatomy. All patients had situs solitus of the atria with concordant atrioventricular and ventriculoarterial connection. A malalignment type of VSD was present in nine patients (1 child with previous VSD closure) and long segment PA was present in six. Four patients had a previous conduit connection of the RV to the pulmonary artery branches. Five patients had an associated ostium secundum atrial septal defect. All children had stenotic (conduit) or atretic (native) RV outflow with severely stenotic or diminutive branch pulmonary arteries, which were discontinuous in two (20\%). The disease of the native pulmonary arteries was bilateral in six patients and unilateral in four. In addition, major AP collateral arteries persisted in six patients (bilateral in 4 patients and unilateral in 2), supplying an average of 12 bronchopulmonary segments. In these patients with $\mathrm{ToF} /$ $\mathrm{PA} /$ major AP collateral arteries, the true pulmonary arteries provided for perfusion of an average of 8 segments (Table II). The preoperative peak right ventricular/left ventricular pressure ratio (pRV/pLV) ranged from 0.92 to 1.00 (mean $0.98 \pm 0.05$ ).

Previous operations. Nine of 10 patients (90\%) in our series had previously undergone 1 to 4 surgical procedures (median 3) at different institutions (Table II). A total of 25 operations had been done on 9 patients: 8 of 9 patients had received at least one procedure through a thoracotomy and one through a median sternotomy, whereas one infant had only had a previous right thoracotomy. Four patients had undergone 8 procedures to establish RVpulmonary artery continuity, including 5 homograft conduit and 2 polytetrafluoroethylene valveless tube graft implants and 1 central shunt construction. One of these 4 patients had also received VSD closure (Table II).

Surgical technique. All infants and young children (younger than 5 years old) received a single injection of narcotic analgesic drug in the epidural space. The older children and adolescents had a permanent catheter inserted into the epidural space, which allowed subsequent administration of narcotic analgesics in the postoperative recovery phase.

Through a submammary skin incision extending laterally to the midaxillary line, both pleural cavities were entered at the level of the fifth intercostal space. The internal thoracic artery and vein were divided and the distal third of the body of the sternum was opened with a saw. In children with previously placed conduits in the right side of the heart, mobilization of the tenacious adhesions for a length of 1 to $2 \mathrm{~cm}$ from the right and left sides of the sternum was sufficient to allow for sawing. Dissection of the anterior mediastinal areolar tissue (or scar tissue, in reoperations) from the inner sternal table was done and two Finochietto retractors were placed for retraction of the chest (Fig. 1). In the dissection of the mediastinal space, great caution was taken to avoid physical trauma to the phrenic nerves. The native pulmonary arteries, when present, were identified and dissected out.

Attention was next devoted to the identification, control, and recruitment of major AP collateral arteries. As many collaterals as possible were ligated, mobilized, and unifocalized before institution of cardiopulmonary bypass. 
Table II. Preoperative anatomy, previous procedures, and operative technique $(n=10$ patients)

\begin{tabular}{|c|c|c|c|c|c|c|}
\hline Patient & $\begin{array}{c}\text { Age } \\
(y r)\end{array}$ & Preop. anatomy & Previous operations & Operaion & Complications & $\begin{array}{c}\text { Follow-up } \\
\text { pRVipLV } \\
\text { value }\end{array}$ \\
\hline 1 & 4 & $\begin{array}{l}\text { VSD, stenotic RV-PA } \\
\text { graft, LPA and } \\
\text { RPA stenosis }\end{array}$ & $\begin{array}{l}\text { R-BT, L-BT, L-unifoc., } \\
\text { RV-PA graft }(\times 2), \\
\text { LPA and RPA stent }\end{array}$ & $\begin{array}{l}\text { LPA and RPA homograft } \\
\text { repair, VSD closure, } \\
\text { RV-PA homograft }\end{array}$ & None & 0.67 \\
\hline 2 & 10 & $\begin{array}{l}\text { ASD, VSD, pulm. } \\
\text { atresia, hypoplastic } \\
\text { PAs, MAPCA (3) } \\
\text { to LUL, LLL, RLL }\end{array}$ & $\begin{array}{l}\text { R-BT, incomplete R- } \\
\text { and L-unifoc. }\end{array}$ & $\begin{array}{l}\text { R- and L-unifoc., LPA } \\
\text { and RPA patch repair, } \\
\text { ASD and VSD closure, } \\
\text { RV-PA homograft }\end{array}$ & None & 0.55 \\
\hline 3 & 6 & $\begin{array}{l}\text { ASD, VSD, stenotic } \\
\text { RV-PA graft, RPA } \\
\text { stenosis, absent } \\
\text { LPA }\end{array}$ & $\begin{array}{l}\text { R-BT, RV-PA graft, } \\
\text { RPA angioplasty }\end{array}$ & $\begin{array}{l}\text { RPA and LPA homograft } \\
\text { tube repair, VSD clo- } \\
\text { sure, RV-PA ho- } \\
\text { mograft }\end{array}$ & $\begin{array}{l}\text { Reexploration because of } \\
\text { bleeding, stent place- } \\
\text { ment for RPA, LPA } \\
\text { restenosis }(8 \mathrm{mo})\end{array}$ & 0.58 \\
\hline 4 & 9 & $\begin{array}{l}\text { ASD, VSD, pulm. } \\
\text { atresia, LPA steno- } \\
\text { sis, MAPCA (2) to } \\
\text { LML, LLL }\end{array}$ & $\begin{array}{l}\text { R-BT, L-BT, incom- } \\
\text { plete unifoc. }\end{array}$ & $\begin{array}{l}\text { R-unifoc., MAPCA (1) } \\
\text { ligation, LPA patch } \\
\text { repair, ASD and VSD } \\
\text { closure, RV-PA ho- } \\
\text { mograft }\end{array}$ & None & 0.38 \\
\hline 5 & 4 & $\begin{array}{l}\text { ASD, VSD, stenotic } \\
\text { RV-RPA graft, dis- } \\
\text { continuous PAs }\end{array}$ & $\begin{array}{l}\text { R-BT, L-BT, RV-RPA } \\
\text { graft }\end{array}$ & $\begin{array}{l}\text { RPA and LPA homograft } \\
\text { tube repair, ASD and } \\
\text { VSD closure, RV-PA } \\
\text { homograft }\end{array}$ & L phrenic nerve palsy & 0.60 \\
\hline 6 & 12 & $\begin{array}{l}\text { VSD, stenotic RV-PA } \\
\text { graft, MAPCA (3) } \\
\text { to RLL, LLL }\end{array}$ & $\begin{array}{l}\text { R-BT, L-unifoc., } \\
\text { RV-PA graft }\end{array}$ & $\begin{array}{l}\text { R- and L-unifoc., } \\
\text { MAPCA (1) ligation, } \\
\text { RPA patch repair, } \\
\text { VSD closure, RV-PA } \\
\text { homograft }\end{array}$ & $\begin{array}{l}\text { RV-PA homograft re- } \\
\text { placement because of } \\
\text { pseudoaneurysm (14 } \\
\text { mo) }\end{array}$ & 0.40 \\
\hline 7 & 15 & $\begin{array}{l}\text { ASD, VSD, pulm. } \\
\text { atresia, LPA steno- } \\
\text { sis MAPCA (2) to } \\
\text { RLL }\end{array}$ & Central shunt & $\begin{array}{l}\text { R-unifoc., MAPCA (1) } \\
\text { ligation, LPA patch } \\
\text { repair, ASD and VSD } \\
\text { closure, RV-PA ho- } \\
\text { mograft }\end{array}$ & None & 0.33 \\
\hline 8 & 0.5 & $\begin{array}{l}\text { VSD, pulm. atresia, } \\
\text { hypoplastic RPA } \\
\text { and LPA, MAPCA } \\
\text { (4) to RLL, RML, } \\
\text { LLL, LUL }\end{array}$ & R-BT & $\begin{array}{l}\text { R- and L-unifoc., RPA } \\
\text { and LPA patch repair, } \\
\text { RV-PA homograft }\end{array}$ & $\begin{array}{l}\text { None, awaiting VSD clo- } \\
\text { sure }\end{array}$ & NA \\
\hline 9 & 0.25 & $\begin{array}{l}\text { VSD, pulm. atresia, } \\
\text { discontinuous PAs, } \\
\text { MAPCA (3) to } \\
\text { RLL, RUL, LLL, } \\
\text { LUL }\end{array}$ & None & $\begin{array}{l}\text { R- and L-unifoc., RPA } \\
\text { and LPA homograft } \\
\text { tube repair, RV-PA } \\
\text { homograft }\end{array}$ & $\begin{array}{l}\text { None, awaiting VSD clo- } \\
\text { sure }\end{array}$ & NA \\
\hline 10 & 13 & $\begin{array}{l}\text { Stenotic RV-PA graft, } \\
\text { LPA stenosis }\end{array}$ & $\begin{array}{l}\text { R-BT, L-BT, RV-PA } \\
\text { graft }(\times 3) \text {, VSD clo- } \\
\text { sure }\end{array}$ & $\begin{array}{l}\text { LPA patch repair, } \\
\text { RV-PA homograft }\end{array}$ & None & 0.30 \\
\hline
\end{tabular}

$P A$, Pulmonary artery; $L P A$, left pulmonary artery; $R P A$, right pulmonary artery; $R$, right; $B T$, Blalock-Taussig; $L$, left; unifoc, unifocalization; $A S D$, atrial septal defect; pulm., pulmonary; $M A P C A$, major AP collateral arteries; $L U L$, left upper lobe; $L L L$, left lower lobe; $R L L$, right lower lobe; $L M L$, left middle lobe; RUL, right upper lobe.

When the hemodynamic values showed increasing instability with consequent desaturation, normothermic bypass was established, and unifocalization was completed.

In detail, after release of the inferior pulmonary ligament and pleural adhesions, exposure of the major AP collateral arteries was gained by simple medial retraction, in sequence, of the left and right lungs out of the pleural space and identification of the thoracic aortic origin of the collaterals (Figs. 2 and 3). Unifocalization procedures were done with the use of native pulmonary or collateral artery tissues and, when these were scarce, with additional pulmonary artery homograft tissue.

The specific steps for unifocalization of collateral arteries and reconstruction of pulmonary arteries were as follows: (1) the collaterals were divided at the origin and the aortic end was oversewn (Fig. 4); (2) unifocalization was done with side-to-side collateral-to-collateral anastomosis, and/or end-to-side collateral-to-native pulmonary 


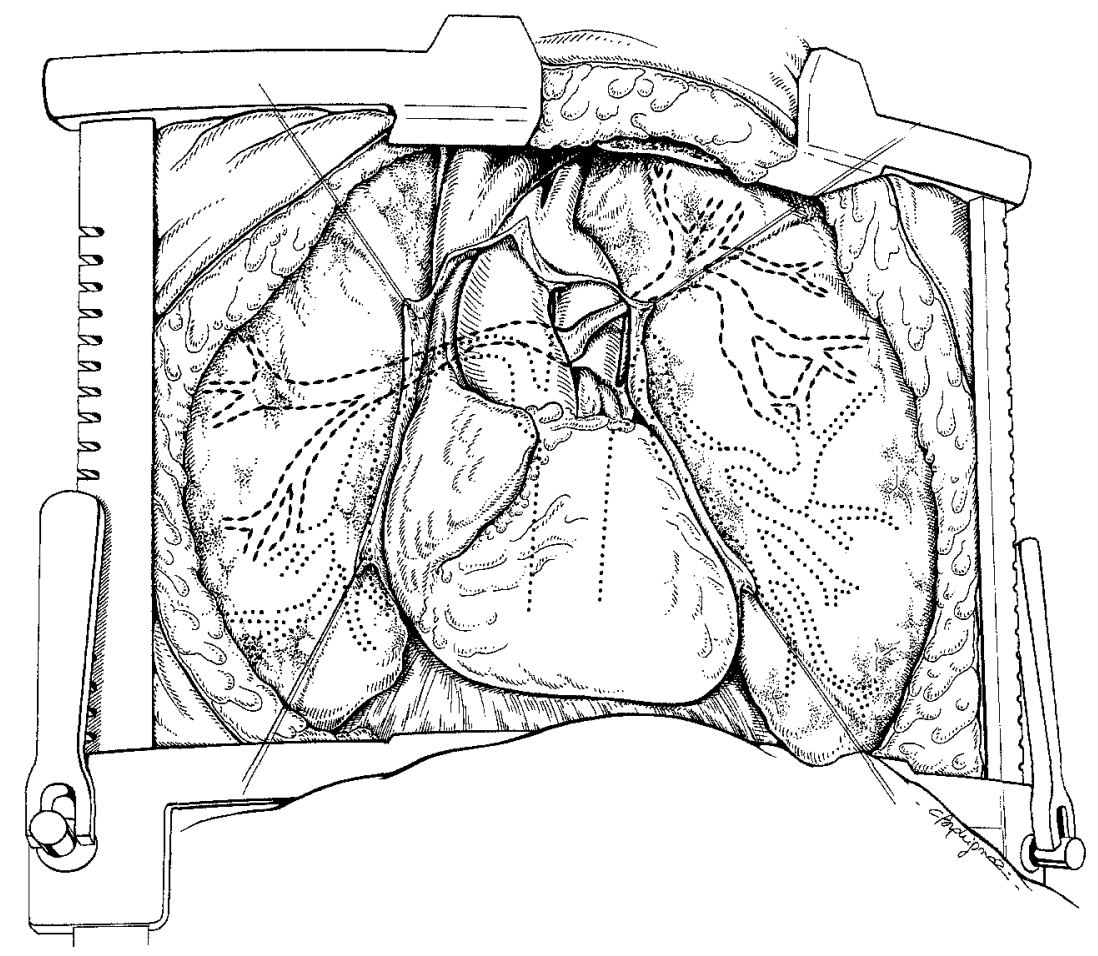

Fig. 1. Diagram showing an operative view of the surgical field after completion of the bilateral thoracosternotomy and insertion of two Finochietto retractors. The thymic lobes have been resected in toto. The pericardial sac has been incised and the margins have been suspended with four stay sutures. Exposure of the heart and great vessels is represented. The topography of true pulmonary arteries (continuous and broken lines) and of AP collateral arteries (dotted lines) offering dual blood supply to both lungs is also shown.

artery anastomosis, and/or end-to-end collateral-to-homograft conduit anastomosis (Fig. 4); (3) the collaterals were mobilized and taken through the posterior mediastinum to the ipsilateral hilum (posterior to the phrenic nerve) (Fig. 5); and (4) the native pulmonary arteries were reconstructed with hilum-to-hilum patches of homograft tissue, when hypoplastic, or replaced with complete tubes of homograft tissue, when discontinuous or absent, during moderately hypothermic $\left(25^{\circ} \mathrm{C}\right)$ cardiopulmonary bypass. The recovered collaterals were then directly (if sufficiently long) or indirectly (by homograft tube interposition) connected to the reconstructed pulmonary arteries (Fig. 5).

Transventricular patch closure of the VSD and pulmonary homograft reconnection of the $\mathrm{RV}$ to the pulmonary arteries were completed during a period of myocardial ischemia. The homograft valved conduits were implanted in the orthotopic position, whenever feasible, keeping the use of pericardial hood extension to a minimum. Transatrial repair of the atrial septal defect, when indicated, was done during rewarming.

Closure of the wound was done after placement of three ( 2 pleural and 1 mediastinal) chest tubes. The thoracotomies were closed with pericostal sutures, and the sternum was reapproximated with two stainless steel sternal wires.

Follow-up. All patients underwent clinical and echocardiographic reassessment. Follow-up ranged from 12 to 26 months, with a median of 17 months. Six patients underwent complete cardiac catheterization at a median follow-up of 15 months.

Statistics. Analysis of variables was done retrospectively, with the use of descriptive statistical methods. All values of continuous variables were expressed as mean plus or minus the standard deviation and median. Comparison between variables was done with Student's paired $t$ test. Actuarial freedom from reintervention for the patient population was estimated by the Kaplan-Meier method.

\section{Results}

Surgical procedures. Ten patients underwent operation for complex ToF/PA: eight children received complete repair of the intracardiac and extracardiac defects, whereas two infants had complete unifocalization of the pulmonary arterial vasculature and connection of it to the RV by a pulmonary homograft conduit (Table II). In the two infants, the presence of diminutive or discontinuous ( 1 infant) native pulmonary arteries was judged to pose a high risk for one-stage repair. The operation was done with cardiopulmonary bypass in all patients (mean 


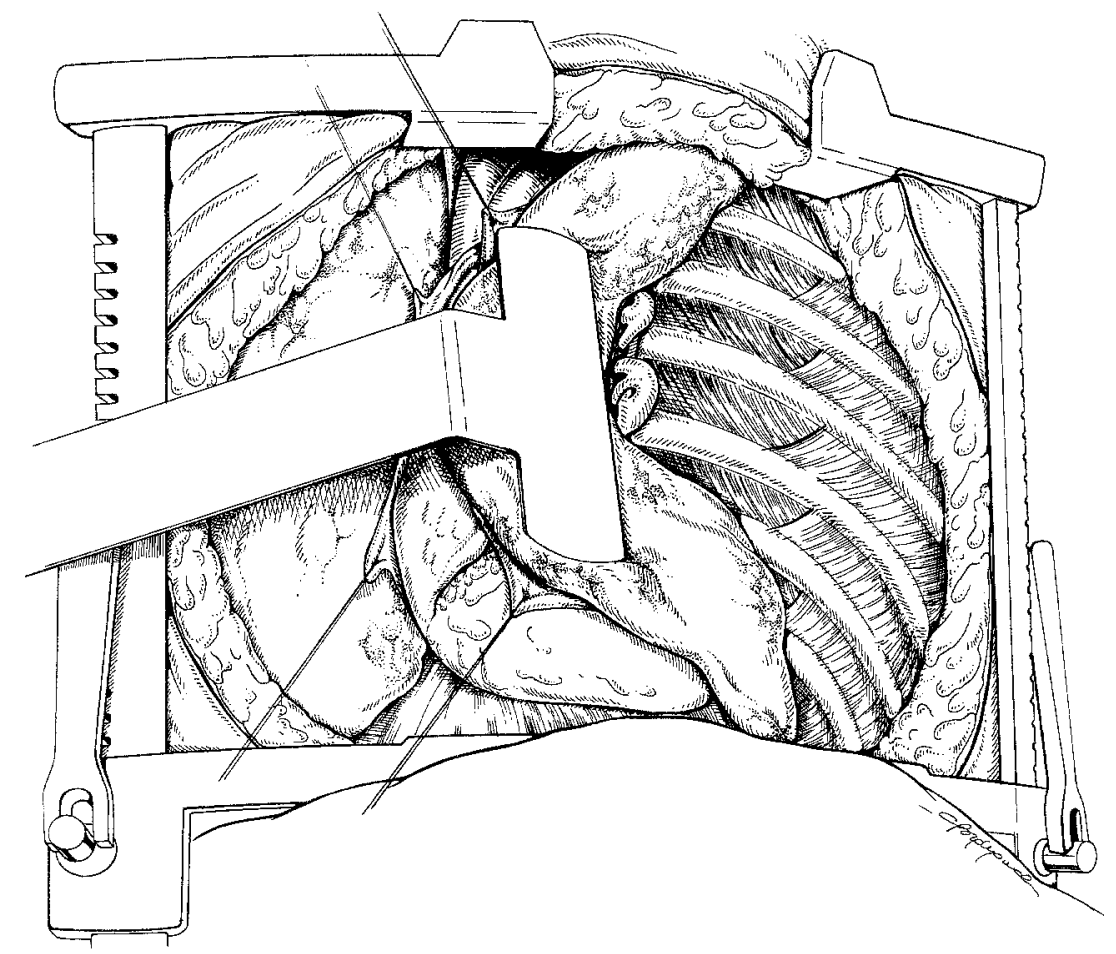

Fig. 2. Diagram showing an operative view after completion of the bilateral thoracosternotomy and insertion of two Finochietto retractors. The four pericardial stay sutures have been suspended to the right side and a lung retractor has been used to retract the left lung medially. Prompt exposure of the descending thoracic aorta and of the origin of two large AP collateral arteries is represented.

duration $110 \pm 45$ minutes, range 56 to $191 \mathrm{~min}$ utes): in the two infants undergoing complete unifocalization, and in one child with previously repaired VSD, repair of the pulmonary artery branches and conduit reconnection with the RV was achieved with the use of moderately hypothermic cardiopulmonary bypass. In the seven remaining children an average period of $51 \pm 18$ minutes of aortic crossclamp time (range 40 to 72 minutes) was needed to complete the intracardiac repair. A total of 17 major AP collateral arteries were identified in 6 patients: 15 were used for unifocalization and branch pulmonary artery reconstruction, whereas 2 were judged inadequate and simply ligated. Central pulmonary artery reconstruction with pulmonary homograft tissue patches or tubes was required in all patients (bilateral angioplasty in 6 patients). In all patients an antegrade, central source of pulmonary blood flow was reestablished with a pulmonary homograft conduit from the $\mathrm{RV}$ to the repaired branch pulmonary arteries. In four patients, this involved removal of a previously implanted, stenotic conduit. The VSD was closed with a patch in seven children, and it had been previously repaired in one. Repair of an associated atrial septal defect was necessary in five patients.

Early results. There were no operative deaths and all patients were discharged from the hospital in good clinical condition. Median duration of mechanical ventilatory support was 2 days (range 1 to 14 days) (Table III). During assisted ventilation, control of postoperative pain was achieved either by intravenous infusion (infants and young children) or by epidural bolus injection (older children) of narcotic analgesic drugs. The median dose of analgesic used was $48 \mu \mathrm{g} / \mathrm{kg}$ per patient. Hemodynamic stabilization was aided by infusion of a median dose of inotropic drugs of $14 \mathrm{mg} / \mathrm{kg}$ per patient prolonged for a median duration of 2 days (range 1 to 5 days). Discharge from the intensive care unit was possible after a median stay of 4 days (range 2 to 15 days) and from the hospital after a median stay of 9 days (range 4 to 19 days) (Table III).

Two major complications occurred in two patients. A 6-year-old girl had a postoperative hemorrhage that necessitated reexploration 4 hours after 


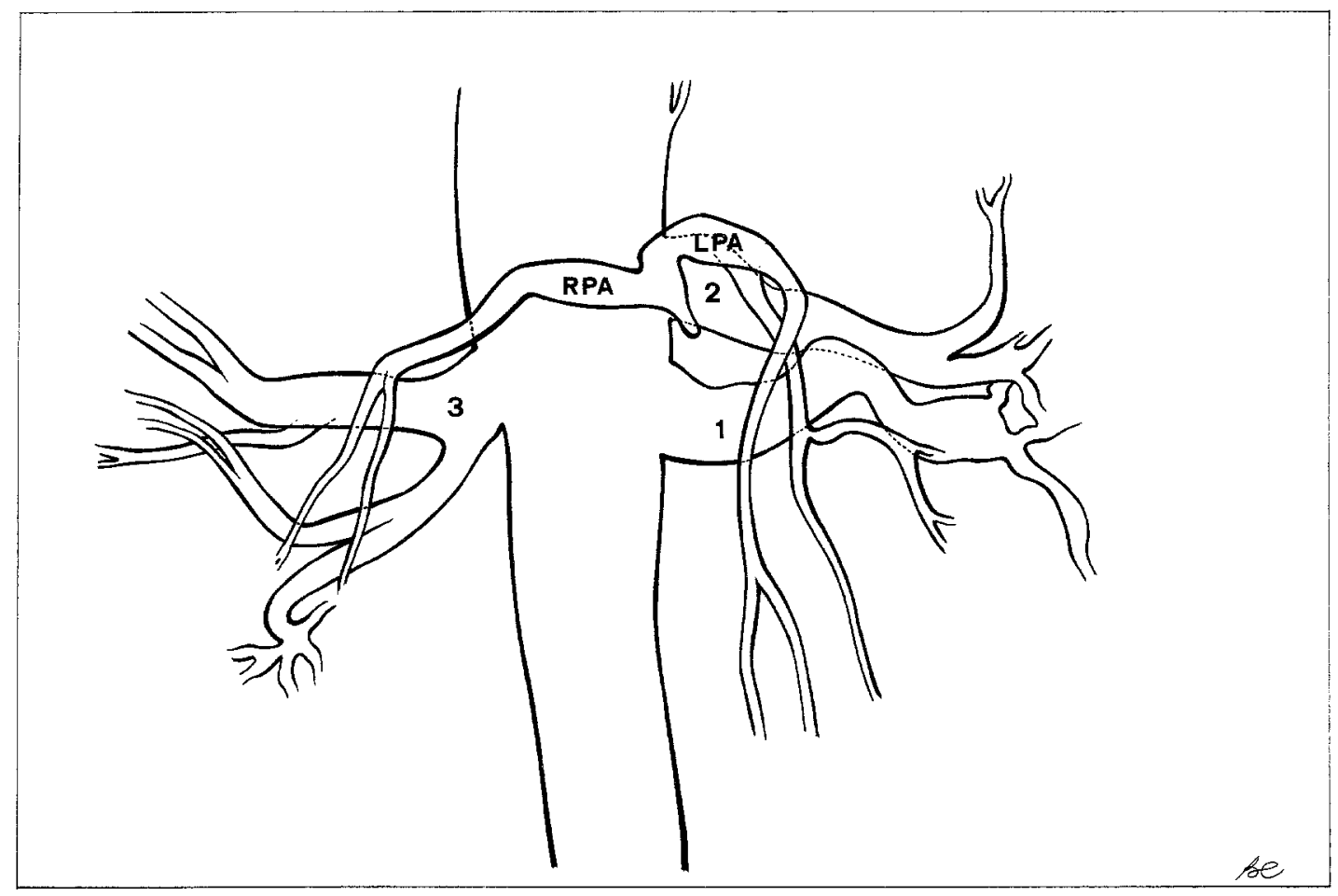

Fig. 3. Diagram representing the preoperative anatomy of the pulmonary circulation in a 6-year-old girl (patient 2). Three large AP collaterals $(1,2,3)$ are evident. The native pulmonary arteries are hypoplastic (right pulmonary artery $[R P A]$ and left pulmonary artery $[L P A]$ ).

admission to the intensive care unit. The proximal stump of a major AP collateral artery in the right posterior mediastinal space was bleeding. Control of the hemorrhage resulted in rapid recovery of the patient, with extubation on postoperative day 2 . The second complication occurred in a 4-year-old boy who had a transient left phrenic nerve palsy that resulted in prolonged postoperative ventilatory insufficiency. The patient was eventually weaned from support 2 weeks after the operation, without the need for surgical plication of the left hemidiaphragm. He had an intensive care unit stay of 15 days and a hospital stay of 19 days, and these data represent the only outliers in our series. No instances of neurologic, systemic, or localized (wound) infectious complications were observed.

Follow-up. There were no late deaths and follow-up was complete in all patients. Midterm assessment occurred at a median time of 18 months after surgical repair (range 12 to 26 months). Clinical status had improved in all patients (mean postoperative New York Heart Association class $1.9 \pm 1.3$ vs $3.4 \pm 0.5, p<0.05)$ and in three administration of cardiac medications had been discontinued. Echo- cardiographic examination was done in all patients and complete catheterization in six. Laboratory investigations confirmed successful correction of complex ToF/PA and a significant decrease in $\mathrm{pRV} / \mathrm{pLV}$ values in all patients having complete repair $(0.98 \pm$ 0.05 vs $0.44 \pm 0.13, p<0.01$ ) (Fig. 6) except in one 6-year-old girl with echocardiographic evidence of systemic RV pressure 8 months after operation. Pulmonary angiography suggested recurrent bilateral branch pulmonary artery stenoses, with a peak pressure gradient of $55 \mathrm{~mm} \mathrm{Hg}$ across the obstructions. Percutaneous balloon pulmonary angioplasty and subsequent bilateral endovascular stent placement resulted in resolution of the RV outflow tract gradient and decrease of $\mathrm{pRV} / \mathrm{pLV}$ values ( $0.92 \mathrm{vs}$ 0.58 , before vs after the procedure). Follow-up echocardiography suggested durable relief of the pulmonary arterial obstruction. Only one patient $(10 \%)$ required reoperation because of echocardiographic evidence of a pseudoaneurysm of the pulmonary homograft conduit 14 months after repair of complex ToF/PA. Reoperation was done with use of the previous clamshell incision, and dissection of the adhesions did not prove excessively cumbersome. At 


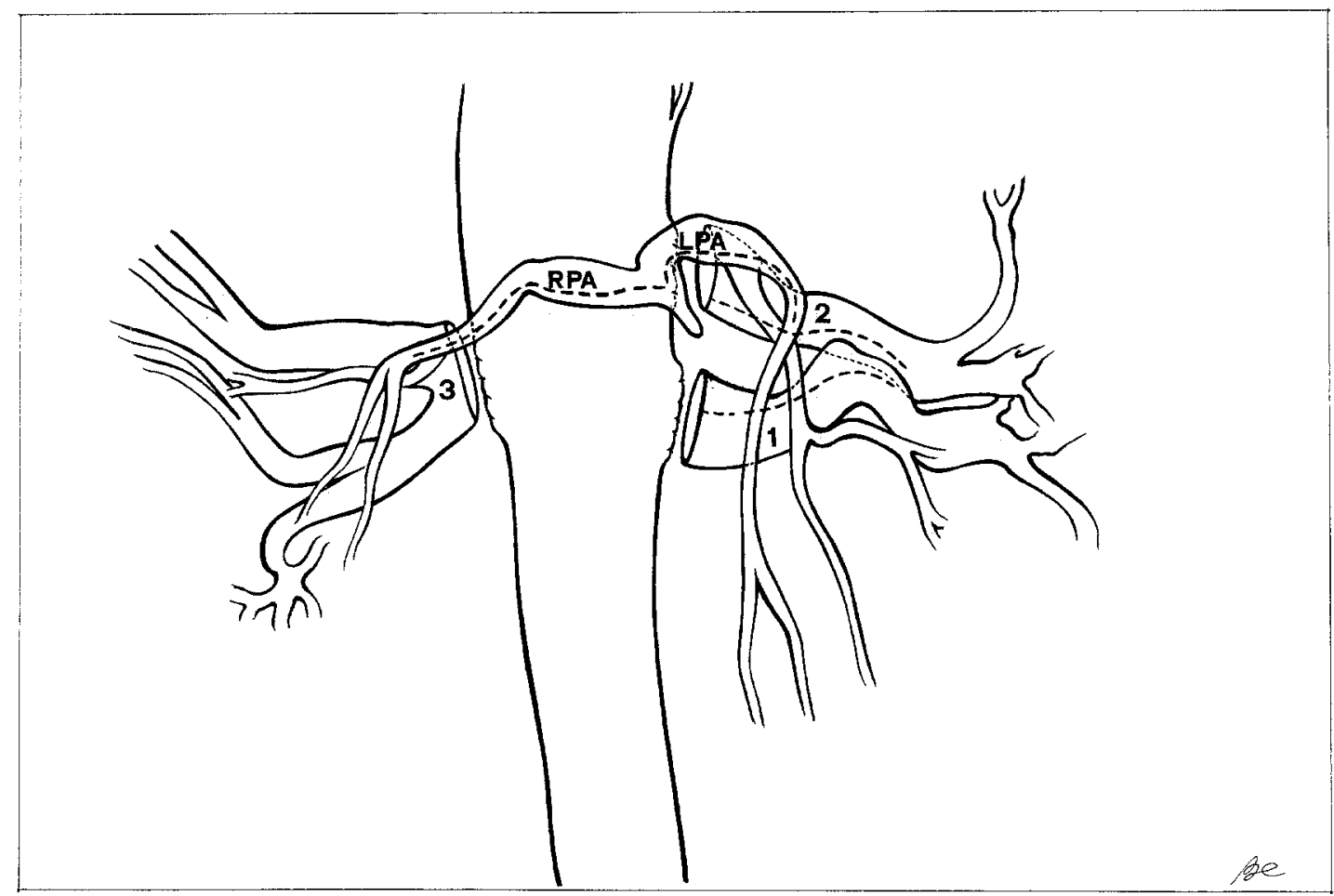

Fig. 4. Intermediate step in the surgical procedure of unifocalization and pulmonary artery reconstruction. The collaterals have been separated from their aortic origin and the left lung collaterals ( 1 and 2 ) have been incised laterally for a side-to-side anastomosis. The native pulmonary arteries have been opened from hilum to hilum. $R P A$, Right pulmonary artery; $L P A$, left pulmonary artery.

the operation two pseudoaneurysms were found: the first at the level of the pericardial patch extension and the second at the distal anastomosis of the graft. A new pulmonary homograft was placed in the orthotopic position with the use of normothermic cardiopulmonary bypass. Recovery of the patient was uneventful and subsequent echocardiographic examination showed no recurrence of the problem. The overall freedom from any reintervention, including percutaneous procedures, for our patient population was $78 \% \pm 11 \%$ at 18 months (Fig. 7). The two infants in our series are still awaiting completion of intracardiac repair.

\section{Discussion}

Historic experience with the surgical management of complex ToF/PA has focused on recruitment of the perfusion of at least $50 \%$ of pulmonary segments before connection of the RV to the pulmonary branches and repair of the intracardiac defects. ${ }^{5}$ Retrospective review of this work at different institutions has made this the standard surgical management of this lesion up to recent years. ${ }^{6-9}$ Because the traditional approach to complex ToF/PA has involved multiple operations aimed at initial unifocalization of arterial blood supply and subsequent establishment of RV-pulmonary artery continuity and VSD repair, patients have been subjected to a median of three surgical procedures (range 2 to 6 ) before complete repair is attained. ${ }^{6-9}$ However, the percentage of children in whom completion of repair has been reached with satisfactory hemodynamics through the staged approach has been low in any given series. ${ }^{6-9}$ Likewise, recent work suggesting a beneficial role for the early establishment of RVpulmonary artery continuity, as opposed to unifocalization, in the growth process of diminutive pulmonary arteries has not resulted in a decrease in the number of procedures nor in a larger proportion of children with successful outcome. ${ }^{10}$

Among the factors responsible for the low yield of staged approaches are progressive loss of the pulmonary vascular bed because of spontaneous occlusion of major AP collateral arteries, the development of pulmonary vascular obstructive disease, and the distortion of central and peripheral branches 


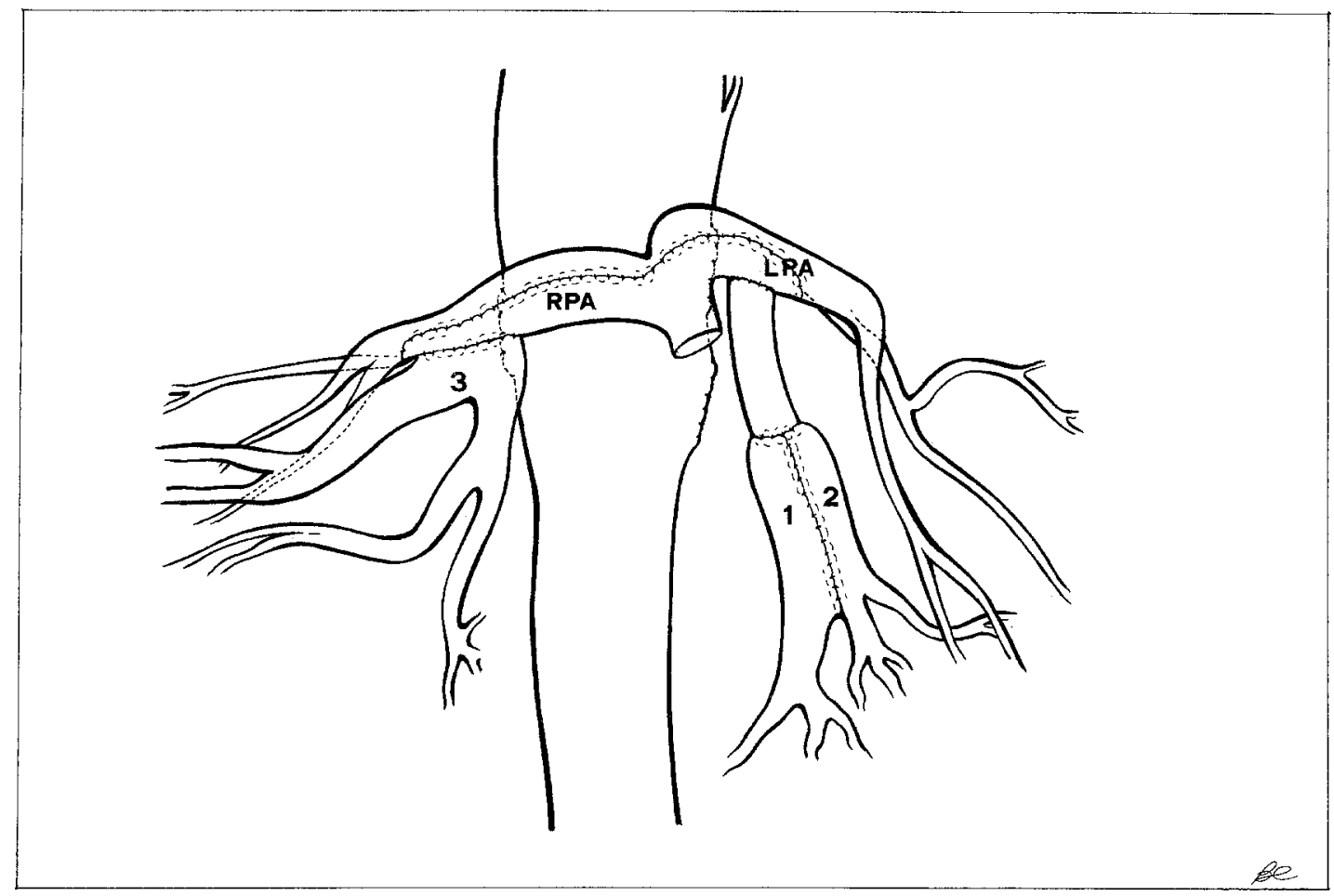

Fig. 5. After homograft patch angioplasty of the branch pulmonary arteries, the reconstructed left collateral ( 1 and 2) is connected end-to-side to the left pulmonary artery $(L P A)$ with use of a homograft tube extension via the posterior mediastinum. The right collateral (3) is anastomosed end-to-side to the right pulmonary artery $(R P A)$ directly.

Table III. Postoperative recovery $(n=10)$

\begin{tabular}{lccr}
\hline \multicolumn{1}{c}{ Parameter } & Range & Mean $\pm S D$ & Median \\
\hline Ventilation duration (days) & $1-14$ & $3.7 \pm 2.1$ & 2 \\
ICU stay (days) & $2-15$ & $5.4 \pm 4.1$ & 4 \\
Hospital stay (days) & $4-19$ & $8.7 \pm 4.6$ & 9 \\
Fentanyl (days) & $1-7$ & $2.3 \pm 1.9$ & 2 \\
Fentanyl total dose $(\mu \mathrm{g} / \mathrm{kg})$ & $24-168$ & $62 \pm 45$ & 48 \\
Inotropes (days) & $1-5$ & $2.3 \pm 1.5$ & 2 \\
Inotropes total dose (mg/kg) & $7-140$ & $16 \pm 10$ & 14 \\
\hline
\end{tabular}

$S D$, Standard deviation; $I C U$, intensive care unit.

caused by scarring from previous palliations. Moving from these observations, Reddy, Liddicoat, and Hanley ${ }^{11}$ have recently started a pilot experience with primary repair of complex forms of ToF/PA. With completion of one-stage unifocalization and, when feasible, intracardiac repair, even in infancy, the use of native, including collateral artery, tissue to reconstruct the pulmonary vascular bed has been maximized. The potential advantages, in terms of limited need for subsequent interventions and, possibly, more "physiologic" growth of the pulmonary artery branches, are intuitive. The technical aspects of the operation done via a median sternotomy, however, may be more demanding in the older child or adolescent and even more so in patients who received previous palliation, because of extensive mediastinal and pleural adhesions. In addition, the reported prevalence of pulmonary complications (40\%), including diaphragmatic paralysis ( 2 patients who required surgical plication), ${ }^{11}$ has not been low, possibly because of suboptimal exposure of thoracic nerves and dissection of peribronchial tissue.

Clamshell approach to complex ToF/PA. Progress in the field of surgical management of complex pulmonary pathologic conditions (bilateral tumors, lung transplantation) and in the techniques of postoperative pain control have permitted the bilateral thoracosternotomy approach to be well tolerated in infants and children. ${ }^{12-14}$

Because complex ToF/PA is a disease process that involves the conotruncal segment, as well as the entire pulmonary arterial bed, the potential advantages of the clamshell incision in terms of exposure are apparent. For a seemingly more extensive surgical approach to be proposed as an alternative in 
pRV/pLV

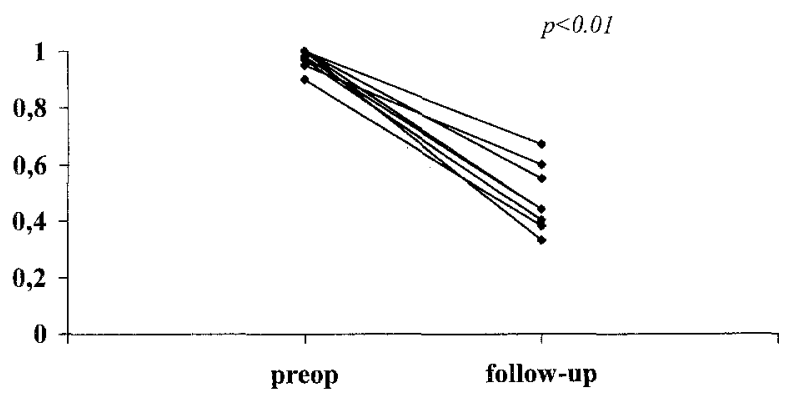

Fig. 6. Diagram of the $\mathrm{pRV} / \mathrm{pLV}$ ratio in 8 of 10 patients undergoing complete repair of complex ToF/PA through a bilateral thoracosternotomy. Comparison of preoperative (preop) ratio with follow-up pressure ratio shows significant decrease in all patients $(0.98 \pm 0.05$ vs $0.44 \pm$ $0.13, p<0.01)$.

selected patients, however, its safety, reproducibility, and efficacy in dealing with the primary disease process need to be demonstrated.

Faced with children in the demanding group of those who had already been subjected to multiple thoracic operations, and pleased with the functional results observed in our pediatric heart-lung and lung transplantation population, we elected to afford infants and children with complex ToF/PA complete one-stage unifocalization and, when feasible, repair using the clamshell approach, as previously suggested by the experience of Puga and coworkers. ${ }^{6}$

The primary advantage with this approach was the complete and bilateral exposure of both central and peripheral pulmonary artery branches and of major AP collateral arteries, which facilitated reconstructive and unifocalization procedures in children with previous thoracotomy (9/10 patients) who had extensive scarring ("frozen hilum"). Reentry of the mediastinal space proved simple with this technique (8/10 patients with 1 previous sternotomy), even in the presence of heavily calcified ("egg shell") conduits ( $4 / 10$ patients), because of the limited need for dissection of the sternal table and the possibility of exposing this area from either side of the sternum. Finally, as opposed to the result with bilateral sequential thoracotomies, access to the heart and great vessels was guaranteed, which thereby allowed simultaneous intracardiac repair.

Analysis of the experience with the clamshell approach to complex ToF/PA suggests that this method is safe. No perioperative deaths were observed and the postoperative course in our patients

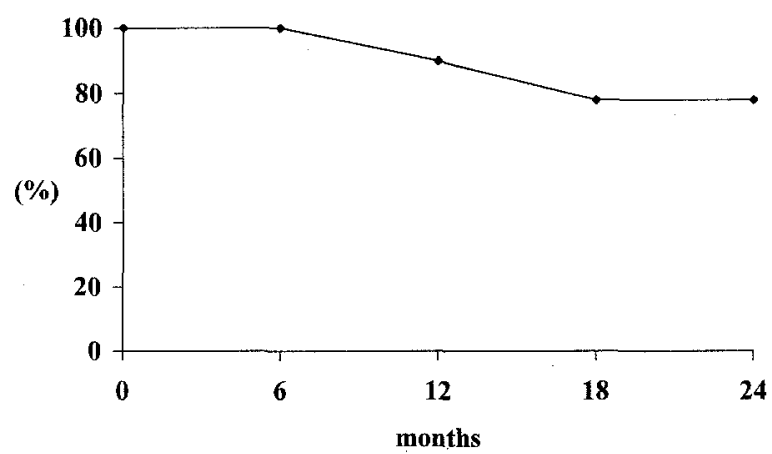

Fig. 7. Actuarial freedom from any reintervention in 10 patients undergoing repair of complex ToF/PA through a bilateral thoracosternotomy between October 1993 and December 1995.

proved to be generally uncomplicated. The routine use of either intravenous or epidural narcotic analgesia facilitated control of postoperative pain and prompt weaning from respiratory support. Indeed, the median hospital stay was contained within a 10-day duration, which is satisfactory given this difficult subset of children. The postoperative hemorrhage that necessitated reexploration $(1 / 10 \mathrm{pa}-$ tients) was clearly unrelated to the incision technique. Pulmonary morbidity was also limited in our series $(10 \%)$, with only one child requiring prolonged mechanical ventilation because of diaphragmatic paresis; weaning was eventually achieved without the need for surgical plication. A more thorough exposure of the phrenic and vagus nerves with the clamshell incision, even in the presence of adhesions, could account for this observation. ${ }^{13}$

This approach appears effective in selected patients with complex ToF/PA. Although not directly comparable to the patients reported on in most published series, our cohort of children represents the extreme end of the spectrum. All children had severe symptoms at operation, six still had a multifocal arterial blood supply to the lungs, and all had hemodynamically critical obstructions of the pulmonary arteries, including severely hypoplastic or discontinuous branches. Despite the preoperative anatomic conditions, the midterm clinical and functional follow-up of our patients demonstrated excellent survival and lasting hemodynamic benefit in infants having complete unifocalization (2 patients) and in children having complete repair ( 8 patients) (Fig. 6). The prevalence of recurrent branch pulmonary artery stenosis $(10 \%$ in the present series) was not higher than that in other 
reported data, ${ }^{10,11}$ and recurrent lesions proved amenable to percutaneous interventional procedures. We observed one case of aneurysmal dilation of the homograft conduit in a child with an otherwise acceptable $\mathrm{pRV} / \mathrm{pLV}$ ratio (0.55), and this necessitated replacement of the graft. Though this is a renowned complication of homografts exposed to high perfusion pressure, ${ }^{10}$ we believe there is an additional causative role of the pericardial hood extension at the base of the conduit. Aware of this potential complication, we have made an effort to implant the homografts in an orthotopic position. Overall freedom from any reintervention was gratifying in our experience (Fig. 7).

On the basis of the encouraging results with a selected group of children with complex ToF/PA who had undergone previous operation, we have chosen to use the clamshell approach also for complete onestage unifocalization and early establishment of RVpulmonary artery connection in newborn infants.

Limitations of the study. Because this analysis encompasses the severe end of the spectrum of complex ToF/PA, both the number of patients and the retrospective, nonrandomized character of the study do not allow meaningful statistical assessment. In addition, our patient population largely differs from that of most previously published works, which makes comparison difficult..$^{6-11}$ Further, the potential advantage of the present approach in terms of reduction of procedures to achieve complete repair can only be postulated because most of our patients had already undergone multiple operations elsewhere. Finally, there are some theoretic disadvantages of the bilateral thoracosternotomy technique, including sacrifice of bilateral internal thoracic arteries and longer extent of the incision.

Conclusions. In conclusion, our experience demonstrates that complete unifocalization, reconstruction of hypoplastic or distorted pulmonary artery branches, and complete repair of complex ToF/PA can be done in one stage with use of the clamshell approach. This technique appears safe and effective, particularly in dealing with infants and children who have undergone previous operations.

\section{REFERENCES}

1. Liao P, Edwards WD, Julsrud PR, Puga FJ, Danielson GK, Feldt RH. Pulmonary blood supply in patients with pulmonary atresia and ventricular septal defect. J Am Coll Cardiol $1985 ; 6: 1343-50$.

2. Jefferson K, Rees S, Somerville J. Systemic arterial supply to the lungs in pulmonary atresia and its relation to pulmonary artery development. Br Heart J 1972;34:418-72.

3. Haworth SG, Macartney FJ. Growth and development of pulmonary circulation in pulmonary atresia with ventricular septal defect and major aortopulmonary collateral arteries. Br Heart J 1980;44:14-24.

4. Rabinovitch M, Herrera-DeLeon V, Castaneda AR, Reid L. Growth and development of the pulmonary vascular bed in patients with tetralogy of Fallot with or without pulmonary atresia. Circulation 1981;64:1234-49.

5. Kirklin JW, Blackstone EH, Shimazaki Y, et al. Survival, functional status, and reoperations after repair of tetralogy of Fallot with pulmonary atresia. J Thorac Cardiovasc Surg 1988;96:102-16.

6. Puga FJ, Leoni FE, Julsrud PR, Mair DD. Complete repair of pulmonary atresia, ventricular septal defect, and severe arborization abnormalities of the central pulmonary arteries. J Thorac Cardiovasc Surg 1989;98:1018-29.

7. Sawatari $\mathrm{K}$, Imai $\mathrm{Y}$, Kurosawa H, Isomatsu $\mathrm{Y}$, Moma K. Staged operation for pulmonary atresia and ventricular septal defect with major aortopulmonary collateral arteries. J Thorac Cardiovasc Surg 1989;98:738-50.

8. Sullivan ID, Wren C, Stark J, de Leval MR, Macartney FJ, Deanfield JE. Surgical unifocalization in pulmonary atresia and ventricular septal defect: a realistic goal? Circulation 1988;78(Suppl):III5-13.

9. Iyer KS, Mee RBB. Staged repair of pulmonary atresia with ventricular septal defect and major systemic to pulmonary artery collaterals. Ann Thorac Surg 1991;51:65-72.

10. Pagani FD, Cheatham JP, Beekman RH, Lloyd TR, Mosca RS, Bove EL. The management of tetralogy of Fallot with pulmonary atresia and diminutive pulmonary arteries. $\mathbf{J}$ Thorac Cardiovasc Surg 1995;110:1521-33.

11. Reddy VM, Liddicoat JR, Hanley FL. Midline one-stage complete unifocalization and repair of pulmonary atresia with ventricular septal defect and major aortopulmonary collaterals. J Thorac Cardiovasc Surg 1995;109:832-45.

12. Johnson J, Kirby CK. Bilateral transpleural exposure of the heart. In: Johnson J, Kirby CK, eds. A handbook of operative surgery: surgery of the chest. Chicago: Year Book, 1958:130-1.

13. Bains MS, Ginsberg RJ, Jones WG, et al. The clamshell incision: an improved approach to bilateral pulmonary and mediastinal tumor. Ann Thorac Surg 1994;58:30-3.

14. Luciani GB, Swilley S, Starnes VA. Pulmonary atresia, intact ventricular septum and major aortopulmonary collaterals: morphogenetic and surgical implications. J Thorac Cardiovasc Surg 1995;110:853-4. 